\title{
Propolis as a green corrosion inhibitor for bronze in weakly acidic solution
}

Simona Varvara ${ }^{a}$, Roxana Bostan ${ }^{a}$, Otilia Bobis ${ }^{b}$, Luiza Găină $\breve{c}^{c}$, Florin Popa ${ }^{d}$, Vicente Mena Ricardo M. Souto

a Department of Exact Sciences and Engineering, “1 Decembrie 1918” University, 11-13 Nicolae Iorga St., 510009 Alba-Iulia, Romania

${ }^{b}$ Life Science Institute, Apiculture and Sericiculture Department, University of Agricultural Sciences and Veterinary Medicine, 3-5 Manastur St., 400028 Cluj-Napoca, Romania

c Department of Organic Chemistry, "Babes-Bolyai” University, 11 Arany Janos St., 400028 Cluj-Napoca, Romania

${ }^{d}$ Materials Science and Engineering Department, Technical University of Cluj-Napoca, 103105 Muncii Avenue, 400641, Cluj-Napoca, Romania

e Department of Chemistry, Universidad de La Laguna, P.O. Box 456, 38200 La Laguna, Tenerife, Spain

\begin{abstract}
In the present work, the inhibitive action of natural propolis on bronze corrosion in a weakly acidic solution containing $\mathrm{Na}_{2} \mathrm{SO}_{4}$ and $\mathrm{NaHCO}_{3}$ at $\mathrm{pH} 5$ was evaluated using multiscale electrochemical techniques, namely potentiodynamic polarization, electrochemical impedance spectroscopy and scanning vibrating electrode technique measurements. The major constituents of propolis were identified by HPLC. Surface characterization was performed by SEM-EDX and AFM analysis. Experiments were performed as a function of the propolis concentration and immersion time in the corrosive electrolyte. The obtained results showed that propolis presents good anticorrosive properties on bronze, acting as a mixed-type inhibitor, but its protective effectiveness is time-dependent. The highest inhibiting efficiency of $98.9 \%$ was obtained in the presence of 100 ppm propolis, after about $12 \mathrm{~h}$ of exposure to inhibitor-containing electrolyte through the stabilization of $\mathrm{Cu}_{2} \mathrm{O}$ on the bronze surface. The inhibitive properties of propolis on bronze corrosion are likely due to the adsorption of its main constituents (flavonoids and phenolic compounds), through the oxygen atoms in their functional groups and aromatic rings, which have been evidenced by FT-IR spectra. The adsorption of propolis on bronze was found to follow Langmuir adsorption isotherm.
\end{abstract}

Keywords: bronze corrosion; propolis; inhibitor; electrochemical techniques; SVET; AFM 


\section{Introduction}

During the past decades, a great number of synthetic compounds have been reported as effective inhibitors for the protection of copper and its alloys against corrosion. Among them there are several inorganic inhibitors (i.e. chromate, molybdate and tetraborate) [1], but far more common are various organic substances, such as triazoles (i.e. benzotriazole) [1-4], thiadiazoles [5-7], imidazoles [8-10], amino acids [11-13], phenothiazine [14], Schiff bases [15] and antibacterial drugs $[16,17]$. Although many of these chemicals present excellent anticorrosive properties, nowadays the uses of some have been limited mostly because of two reasons [2]: their synthesis is often very expensive and they might be toxic or hazardous for human beings and environment, as well. As result, the research trend in the field of corrosion inhibition is orientated toward the goal of developing environmentally-friendly inhibitors [18].

Over the recent years, the use of naturally occurring substances of plant origin, otherwise tagged as "green corrosion inhibitors" has received much more attention because they are incredible sources of natural organic compounds, which are environmentally acceptable, inexpensive, readily available and renewable sources of materials [19]. Green inhibitors can be used in the form of extracts or essential oils. Recent works have reported the plant extracts of Camellia sinensis [2], Egyptian licorice [20], Morinda tinctoria [21], olive [22] and Mimosa [23] leaves, pomegranate fruit-shells [24] as efficient corrosion inhibitors of copper and its alloys in different electrolytes. The inhibition performances of the plant extracts are closely related to the presence in their composition of complex organic species, such as polyphenolic compounds, alkaloids, flavonoids, carbohydrates, amino acids, proteins etc. These organic compounds usually bear polar functional groups containing $\mathrm{N}, \mathrm{S}$ or $\mathrm{O}$ atoms, as well as moieties consisting of triple or conjugated double bonds or aromatic rings, which are the major adsorption centres [25]. Even the presence of tannins, cellulose and polycyclic compounds normally enhances the film formation over the metal surface, thus retarding the corrosion [26]. The anticorrosive efficiency of the plant extracts was found to depend on the metallic substrate, the active organic molecules and the corrosive media [27].

Apart from plant extracts, the bee products (i.e. honey and propolis) are other natural materials that might be efficiently used for the protection of metals and alloys against corrosion. Several studies already attested the good anticorrosive effectiveness of honey on copper [28], tin [29], aluminium [30], C-steel [31], zinc [32], Al-Mg-Si [33] and CuNiFe alloys [34] in various solutions. More recent works have proved that ethanolic extract of propolis is also able to inhibit to a great extent the corrosion of stainless steel in sulfuric acid [35] and carbon steel in aluminium sulphate and chloride solutions [36]. Moreover, Dolabella et al. [37] have 
demonstrated the possibility of using the ethanolic extract of propolis to form a protective coating for mild steel in neutral and near neutral chloride media.

Propolis is a bee hive product with a complex composition, exhibiting valuable pharmacological and biological properties, and one of many natural products with known antioxidant properties [38]. The composition of propolis depends on the place and time of collection and varies greatly with the vegetal source that bees are using as raw material [39]. More than 160 components have been identified so far, among which phenolic compounds, including flavonoids, are the major components [40]. Propolis is currently widely used in medicine due to its antibacterial, antiviral, antifungal and antioxidant properties. The ethanolic extract of propolis is also known for various biological activities, including immunopotentiation, chemopreventive and antitumoral effects [41].

The aim of the present work is to investigate the protective properties of propolis at various concentrations, as a green corrosion inhibitor of bronze in an aerated weakly acidic solution containing $\mathrm{Na}_{2} \mathrm{SO}_{4}$ and $\mathrm{NaHCO}_{3}(\mathrm{pH}$ 5) that simulates acid rain in an urban environment. To the best of our knowledge, propolis has never been used for the purpose of bronze corrosion inhibition studies so far. To this regard, a dark brown propolis sample was selected for the study. The organic species present in the propolis sample were characterized by high performance liquid chromatography with diode array detection (HPLC-DAD) and spectrophotometric measurements. Fourier transform infrared spectroscopy (FT-IR) was used to identify the functional groups and the structural units of the propolis' components. The inhibiting properties of propolis on bronze corrosion were evaluated using a multiscale electrochemical characterization, by combining conventional electrochemical techniques (potentiodynamic polarisation and electrochemical impedance spectroscopy) and the scanning vibrating electrode technique (SVET). The effect of the immersion time in solution containing the optimum concentration of propolis was also studied. The bronze surface morphology in the absence and in the presence of propolis was observed by SEM-EDX and AFM techniques. Several adsorption isotherms were tested for their potential relevance in explaining the adsorptive behaviour of propolis’ components on bronze surface.

\section{Material and methods}

\subsection{Corrosion tests}

The corrosion tests have been performed on a working electrode made of bronze with the following chemical composition (wt. \%): Cu-94.03, Sn-3.31, Pb-0.24, Zn-1.44, Ni-0.25, Fe0.22 and S-0.51. The bronze specimen was embedded in an epoxy resin (Buhler, Epoxycure ${ }^{\mathrm{TM}}$ ), 
leaving a working area of $0.28 \mathrm{~cm}^{2}$. The bronze surface was prepared via an abrading procedure using successive grade of silicon carbide paper grit (from 600 up to 2400), washed thoroughly with distilled water and with ethanol.

The blank corrosive electrolyte was an aqueous solution of $0.2 \mathrm{~g} \mathrm{~L}^{-1} \mathrm{Na}_{2} \mathrm{SO}_{4}+0.2 \mathrm{~g} \mathrm{~L}^{-1}$ $\mathrm{NaHCO}_{3}$, acidified to $\mathrm{pH}=5$ by addition of dilute $\mathrm{H}_{2} \mathrm{SO}_{4}$. The influence of various concentrations of propolis on the bronze corrosion was studied at room temperature $\left(20{ }^{0} \mathrm{C}\right)$. All corrosion tests were performed in the electrolytes, under non-stirred and naturally aerated conditions.

\subsection{Inhibitor}

A dark-brown solid propolis sample collected from Henan province (China) was used in the present study. $1 \mathrm{~g}$ of solid propolis was dissolved in $100 \mathrm{~mL}$ ethanol to give a stock solution of $1 \%(\mathrm{w} / \mathrm{v})$ inhibitor. Then, appropriate volumes of $1 \%$ propolis solution were added into the blank corrosive electrolyte in order to obtain electrolytes containing different concentrations of propolis $\left(C_{\text {Inh }}\right)$ in the range of 50 to $500 \mathrm{ppm}$. For the corrosion tests, the ethanol volume was kept at the same level (5\%) in the blank and in all propolis-containing solutions.

\subsection{Electrochemical measurements}

A three-electrode cell was used for the electrochemical experiments. The counterelectrode was a large platinum grid, and a calomel electrode in saturated $\mathrm{KCl}$ (SCE) was used as reference electrode. The electrochemical measurements were carried out using a PAR model 2273 potentiostat. Before each experiment, the bronze electrode was left at the open circuit potential for $1 \mathrm{~h}$ in the corrosive solution.

Polarization curves were recorded at constant sweep rate of $10 \mathrm{mV} \mathrm{min}{ }^{-1}$, in a wide potential range of $\pm 200 \mathrm{mV} v$ s. open-circuit potential (OCP) from the cathodic to the anodic direction.

Electrochemical impedance spectroscopy measurements (EIS) were performed at OCP after $1 \mathrm{~h}$ immersion of the bronze electrode in the corrosive solution in order to ensure that no evolution of the system during the experiments might occur. The impedance spectra were acquired in the frequency range of $10 \mathrm{kHz}$ to $10 \mathrm{mHz}$ at 5 points per $\mathrm{Hz}$ decade with an $\mathrm{AC}$ voltage amplitude of $\pm 10 \mathrm{mV}$. The measurements were carried out during $48 \mathrm{~h}$ and the impedance data were collected every $2 \mathrm{~h}$. The obtained impedance data were modelled using ZSimpWin 3.21 software. 
Scanning vibrating electrode technique (SVET) measurements were performed using the instrument produced by Applicable Electronics, with platinized Pt/Ir (80\%/20\%) probes of 10-20 $\mu \mathrm{m}$ diameter as probe. The small electrochemical cell was completed with the inclusion of two platinized Pt/Ir wires serving as ground and reference, and contained approximately 5 $\mathrm{mL}$ of $0.2 \mathrm{~g} \mathrm{~L}^{-1} \mathrm{Na}_{2} \mathrm{SO}_{4}+0.2 \mathrm{~g} \mathrm{~L}^{-1} \mathrm{NaHCO}_{3}$ (pH 5) solution. The probe was vibrated normal to the surface at $165 \mathrm{~Hz}$ frequency, and the vibration amplitude was twice the diameter of the tip. The measured potential differences were converted into ionic currents by means of a calibration routine based on the use of a model current source and taking in account the solution resistivity. The ionic current distribution maps were recorded in constant height mode, i.e. in a plane parallel to the surface located $100 \mu \mathrm{m}$ above the sample. The sample was left unpolarised throughout the measurements.

\subsection{FT-IR measurements}

The solid propolis sample was dried at $105{ }^{\circ} \mathrm{C}$, pressed into a $\mathrm{KBr}$ pellet and then analysed in a Perkin Elmer BX FTIR spectrometer, in the frequency range of 4000 to $600 \mathrm{~cm}^{-1}$.

\subsection{Surface topography characterization}

For morphological studies, the bronze surface was prepared by keeping the electrodes during $48 \mathrm{~h}$ in the corrosive solution in the absence and in the presence of propolis. Then, the specimens were washed gently with water, carefully dried and characterized without any further treatment by scanning electron microscopy (SEM) and atomic force microscopy (AFM). The SEM measurements were performed using a JEOL JSM 5600 LV microscope, equipped with EDX spectrometer - Oxford Instruments (INCA 200 software). The energy of the acceleration beam employed was $15 \mathrm{kV}$ and the given results are 250× magnifications. AFM instrument was a Nano-Observer from CS Instruments operated in tapping mode.

\subsection{Chemical characterization of propolis}

The total polyphenolic and total flavonoid contents of $1 \%(\mathrm{w} / \mathrm{v})$ propolis solution were determined by spectrophotometric analysis. The identification and quantification of individual phenolic compounds from the propolis solution was performed by high performance liquid chromatography with diode array detection (HPLC-DAD).

\subsubsection{Chemicals}


Phenolic acids and flavonoids (gallic, sinapic, ferulic, caffeic, p-cumaric, rosmarinic, cicoric and quercetin, apigenin, isovitexin, hyperoside, quercitrin, quercetin-3-glycside, apigenin-7-glyciside, luteolin-7-glycoside) were purchased from Karl-Roth (Karlsruhe, Germany), Sigma-Aldrich (St. Louis, USA) and Fluka (Buchs, Switzerland). Folin Ciocâlteu reagent, aluminium chloride, sodium carbonate were purchased from Sigma-Aldrich (St. Louis, USA). Analytical grade solvents were used for HPLC and spectrophotometric determinations. Deionized water $\left(0.067 \mu \mathrm{S} \mathrm{cm} \mathrm{cm}^{-1}\right)$ was produced with a Millipore Milli-Q device.

\subsubsection{Bioactive compounds determination}

Total soluble phenolic compounds from the propolis solution were determined using Folic-Ciocâlteu reagent, according to the method of Singleton et al. [42] with some modifications [43]. A volume of $1.5 \mathrm{~mL}$ of propolis solution was placed in a volumetric flask $(25 \mathrm{~mL})$ and diluted to sign with methanol. From this solution $0.5 \mathrm{~mL}$ were transferred in another $25 \mathrm{~mL}$ volumetric flask with $15 \mathrm{~mL}$ water. $2 \mathrm{~mL}$ Folin-Ciocâlteu reagent was added and after $5 \mathrm{~min}, 3 \mathrm{~mL}$ of $20 \%$ (w/v) sodium carbonate was added and brought to sign with distilled water. Samples were incubated in the dark for $2 \mathrm{~h}$ at room temperature and the absorbance of the mixture was read at $760 \mathrm{~nm}$ against a blank consisting of methanol, FolinCiocâlteu reagent and sodium carbonate. For the calibration curve, a stock solution of pinocembrin:galangin 2:1 was used, serial dilutions were made and subjected to the same protocol $\left(y=0.540 x-0.005, \quad r^{2}=0.999\right)$. Results were expressed as pinocembrin:galangin equivalents.

The total flavone/flavonol content was determined using a method adapted by ArvouetGrand et al. [44] using a standard curve of quercetin $\left(0.5-0.01 \mathrm{mg} \mathrm{mL}^{-1}\right)(y=11.11546 x-$ $\left.0.00664 ; r^{2}=0.9988\right)$. In brief, $1 \mathrm{~mL}$ of diluted propolis solution was placed in a $25 \mathrm{~mL}$ volumetric flask containing $15 \mathrm{~mL}$ methanol. $0.5 \mathrm{~mL}$ of $5 \%$ aluminium chloride was added, mixed thoroughly, brought to sign with methanol and absorption readings at $415 \mathrm{~nm}$ using a Pharmaspech UV-1700 Shimadzu spectrophotometer (Japan) were taken against a blank sample. The flavonoid content was expressed as mg of quercetin equivalents.

\subsubsection{HPLC analysis}

Separation of phenolic acids and flavonoids was carried out on a Supelcosil LC-18 column (250 $\mathrm{mm} \times 4.6 \mathrm{~mm}, 5 \mu \mathrm{m})$, using as mobile phases methanol:acetic acid: $\mathrm{H}_{2} \mathrm{O}$ 10:2:88 (solvent A) and methanol:acetic acid: $\mathrm{H}_{2} \mathrm{O}$ 90:3:7 (solvent B), using the following linear gradient of A-B: 10 min, 85:15; 30 min, 50:50; 45 min, 15:85; 55 min, 100:0 (total run time 60 
min). A Shimadzu LC-10ADVP system (Shimadzu Instruments, Japan) consisting of SCL10AVP system controller, SPP-M20A Prominence Diode Array Detector, LC-10ADSP binary pumps, CTO-10AVP column oven and SIL-10AF auto sampler was used for the separation of individual phenolics. Phenolic acids and flavonoids chromatograms were registered at 254, 270, 320 and $340 \mathrm{~nm}$. Co-chromatography with standards was also performed, for identification of phenolic compounds from the sample. Concentration of each individual compound was calculated based on external standard method, using calibration curves of each compound, after comparing the retention time and UV spectra with reference standards.

\section{Results and discussion}

\subsection{FT-IR measurements}

Fourier transform infrared spectroscopy was used to identify the functional groups and the structural units of the propolis components.

In the FT-IR spectrum of propolis, presented in Fig. 1, several characteristic absorption bands were identified, i.e. stretching vibrations of intermolecular associated hydroxyl groups, $v_{\mathrm{O}-\mathrm{H}} \sim 3368 \mathrm{~cm}^{-1}(\mathrm{br})$, symmetrical and asymmetrical vibrations for alkyl units, $v_{\mathrm{CH} 2} 2926$ and $2851 \mathrm{~cm}^{-1}(\mathrm{~m})$, vibrations for aromatic rings $v_{\mathrm{C}=\mathrm{C}} 1514 \mathrm{~cm}^{-1}(\mathrm{~m})$ and phenols moiety $v_{\mathrm{C}-\mathrm{OH}} 1147$ $\mathrm{cm}^{-1}(\mathrm{i})$.

Moreover, the absorption bands belonging to some functionalities $\alpha, \beta$-unsaturated carboxylic acid $v_{\mathrm{C}=\mathrm{O}} 1692 \mathrm{~cm}^{-1}(\mathrm{i}), \alpha, \beta$-unsaturated ketone $v_{\mathrm{C}=\mathrm{O}} 1636 \mathrm{~cm}^{-1}$ (fi) and $v_{\mathrm{C}=\mathrm{C}} 1602$ $\mathrm{cm}^{-1}$ (fi), alkyl-ketone units $\delta_{\mathrm{C}-\mathrm{H}} 1514 \mathrm{~cm}^{-1}(\mathrm{~m})$, alkyl-aril ethers $v_{\text {as C-O-C }} 1263 \mathrm{~cm}^{-1}$ (fi) and $v_{\text {sim }}$ C-O-c $1028 \mathrm{~cm}^{-1}(\mathrm{~m})$ were also assigned. These results suggest that propolis might have anticorrosive properties since it contains oxygen atoms in functional groups $(\mathrm{O}-\mathrm{H}, \mathrm{C}=\mathrm{C}, \mathrm{C}=\mathrm{O})$ and aromatic rings, which meets the general criteria of typical corrosion inhibitors [2].

\subsection{Polarization curves}

The influence of propolis on the polarization behaviour of bronze in $0.2 \mathrm{~g} \mathrm{~L}^{-1} \mathrm{Na}_{2} \mathrm{SO}_{4}+$ $0.2 \mathrm{~g} \mathrm{~L}^{-1} \mathrm{NaHCO}_{3}(\mathrm{pH}$ ) solution was evaluated based on the potentiodynamic polarization curves. The bronze electrode samples were left in the corrosive solution for either 1 or $48 \mathrm{~h}$, and then the polarization curves were plotted starting from the cathodic to the anodic potentials.

Fig. 2 shows the cathodic and anodic polarization curves obtained in the presence of propolis at various concentrations in $0.2 \mathrm{~g} \mathrm{~L}^{-1} \mathrm{Na}_{2} \mathrm{SO}_{4}+0.2 \mathrm{~g} \mathrm{~L}^{-1} \mathrm{NaHCO}_{3}$ (pH 5), after immersion for 1 and 48 h, respectively. 
From Fig. 2 it is clear that both the anodic dissolution of bronze and cathodic oxygen reduction reactions were inhibited by the addition of propolis into the corrosive electrolyte. The inhibitive effect of propolis on these reactions appeared to be more pronounced at longer exposure times.

Electrochemical parameters, including the corrosion potential $\left(E_{\text {corr }}\right)$, the cathodic $\left(\beta_{\mathrm{c}}\right)$ and anodic $\left(\beta_{\mathrm{a}}\right)$ Tafel slopes, and the corrosion current density ( $\left.i_{\text {corr }}\right)$ were calculated by Tafel extrapolation method and the results obtained at different immersion times are presented in Table 1. It also contains the inhibiting efficiency $(z)$ values calculated according to following equation:

$$
z(\%)=\frac{i_{\text {corr }}^{0}-i_{\text {corr }}}{i_{\text {corr }}^{0}} \times 100
$$

where $i_{\text {corr }}^{\text {o }}$ and $\boldsymbol{i}_{\text {corr }}$ are the values of the corrosion current densities in absence and in presence of the propolis, respectively.

As it can be observed in Table 1, the addition of propolis at all tested concentrations significantly reduced the corrosion current density values, as well for the short as for the long immersion period. In the investigated experimental conditions, the lowest $i_{\text {corr }}$ values were recorded in the presence of $100 \mathrm{ppm}$ propolis. Beyond this threshold concentration, the $i_{\text {corr }}$ values slightly increased, but they remained considerably lower as compared to the blank sample. These results demonstrated the ability of propolis to retard the corrosion process, most likely due to the adsorption of propolis' components on the bronze surface, through the oxygen atoms within their functional groups and the aromatic rings.

The corrosion potentials shifted towards more positive values in the presence of propolis as compared to the $E_{\text {corr }}$ value corresponding to the blank corrosive solution (Table 1). Disregarding the exposure time to propolis-containing electrolytes, the maximum displacement of the $E_{\text {corr }}$ values in the range of $62-64 \mathrm{mV}$ was obtained in the presence of $500 \mathrm{ppm}$ inhibitor. This behavior suggests that propolis acts as a mixed-type inhibitor [2].

As expected, the inhibition effectiveness of propolis strongly depended on its concentration and exposure time to corrosive electrolyte. From Table 1 is obvious that propolis exhibited only a moderate anticorrosive effect on bronze during the first hour of immersion. Thus, the calculated $z$ value was low (34.5\%) in the solution containing 50 ppm propolis, but it progressively increased with the inhibitor concentration and reached the maximum value of 87.5\% in the presence of 100 ppm propolis. By prolonging the bronze exposure to inhibitorcontaining electrolytes up to $48 \mathrm{~h}$, a significant increase of the propolis inhibitive effect was 
noticed for all investigated concentrations (Table 1). The highest $z$ value of 95\% was achieved after $48 \mathrm{~h}$ of bronze immersion in $100 \mathrm{ppm}$ propolis-containing electrolyte. Above this concentration, the anticorrosive proprieties of propolis slightly decreased for both short and long exposure times.

The relatively poor protection afforded by propolis on bronze at the initial immersion compared to the results obtained at longer exposure suggests that the formation of a highly protective and stable inhibitor layer on bronze surface might need more time than $1 \mathrm{~h}$ to evolve completely. Similar results were obtained for brass corrosion inhibition by Camellia sinensis extract in acidic and neutral $0.1 \mathrm{M} \mathrm{Na}_{2} \mathrm{SO}_{4}$ solution [2].

Independently of the immersion time in the electrolyte, the changes of the anodic $\left(\beta_{\mathrm{a}}\right)$ and cathodic $\left(\beta_{c}\right)$ Tafel slopes observed in the presence of propolis confirm that the kinetics of anodic and cathodic processes were affected by the presence of propolis in the corrosive solution, but no definite trend was observed.

\subsection{Electrochemical impedance spectroscopy}

EIS measurements were carried out at the open circuit potential during $48 \mathrm{~h}$, and the impedance data were collected every $2 \mathrm{~h}$.

Fig. 3 shows typical impedance diagrams obtained for bronze corrosion in $0.2 \mathrm{~g} \mathrm{~L}^{-1}$ $\mathrm{Na}_{2} \mathrm{SO}_{4}+0.2 \mathrm{~g} \mathrm{~L}^{-1} \mathrm{NaHCO}_{3}(\mathrm{pH}$ ) in the absence and in presence of various concentrations of propolis at different immersion times. The experimental data are presented in Fig. 3 as Nyquist and Bode plots, respectively. The fitted curves represented by lines with crosses are shown together with the experimental data represented by symbols.

It can be seen in Fig. 3 that the complex impedance diagrams were characterized by a capacitive behaviour with two depressed semicircles, although their separation was not always clear, especially in the early immersion period. This behaviour is typical for bronze corrosion in weakly aggressive media [45].

The large increase of the low-frequency limit of the impedance (i.e. polarization resistance) noticed in the presence of propolis confirms its inhibiting action on bronze corrosion. This effect was enhanced at long exposure, as proved by the significant enlargement of the impedance amplitude as the immersion time elapsed.

Based on two apparent time constants, the impedance spectra obtained in the absence and in the presence of propolis were analysed using an electrical equivalent circuit consisting of two parallel $R-Q$ couples (Fig. 4). 
In the equivalent circuit illustrated in Fig. 4, a constant phase element (CPE), represented by the terms $Q$ and $n$, was used instead of an ideal capacitor. The CPE impedance is described by the following equation [46]:

$$
Q=Z_{\mathrm{CPE}(\omega)}=\left[C(j \omega)^{n}\right]^{-1}
$$

where $Q$ represents a pre-exponential factor, which is a frequency-independent parameter with dimensions of $\Omega^{-1} \mathrm{~cm}^{-2} \mathrm{~s}^{n} ; j$ is the imaginary number; $\omega=2 \pi f$ is the angular frequency in rad $\mathrm{s}^{-1} ; n$ is the exponent which defines the character of frequency-dependence $(-1 \leq n \leq 1)$. The values of $n$ are associated with the non-uniform distribution of current because of surface roughness and other non-homogeneities, adsorption of inhibitors, formation of porous layers and the variations in properties or compositions of surface layers [7]. Depending on the value of the exponent $n$, CPE behaves as a resistor with the resistance $R(n=0)$, or a capacitor with the capacitance $C(n=1)$.

The origin of each element in Fig. 4 was allocated as follows [45]: $R_{\mathrm{e}}$ is the solution resistance; the high frequency elements $\left(Q_{\mathrm{d}}-R_{\mathrm{ct}}\right)$ correspond to double layer capacitance $\left(C_{\mathrm{dl}}\right)$ in parallel with the charge transfer process $\left(R_{\mathrm{ct}}\right)$, while the low frequency circuit represented by $Q_{\mathrm{F}}-R_{\mathrm{F}}$ may be ascribed to a redox process involving the corrosion products accumulated at the interface (presumably $\mathrm{Cu}_{2} \mathrm{O}$ ). The coefficients $n_{d l}$ and $n_{F}$ allowed the depressed feature of the impedance spectra as revealed in Nyquist diagram to be reproduced.

It is obvious from Fig. 3 that the fitted data matched almost perfectly to the experimental results in the whole frequency domain. The applicability of the model used for the fitting procedure was also confirmed by the $\chi^{2}$ (Chi-square) values that were typically of the order of $10^{-4}-10^{-3}$. The error percentages corresponding to each component of the equivalent circuit were generally below $10 \%$, confirming once more that the experimental impedance adjusted well to the proposed equivalent circuit.

The values of the pseudo-capacitances $(C)$ associated with CPEs were recalculated using the equation:

$$
C=\left(R^{1-n} Q\right)^{1 / n}
$$

Time-evolution of the calculated $R-C$ parameters corresponding to bronze corrosion in the absence and in the presence of various concentrations of propolis is illustrated in Fig.5.

As seen in Fig. 5a, at the initial immersion time, the charge-transfer resistances were only slightly higher in the presence of propolis as compared to the $R_{\mathrm{ct}}$ value of the blank solution. By increasing the exposure time, a progressive rise of the $R_{\mathrm{ct}}$ values took place in all propolis-containing electrolytes, except for the solution with $50 \mathrm{ppm}$ inhibitor, where no 
significant differences could be noticed with respect to the blank solution. Furthermore, as the propolis concentration increased, the $R_{\mathrm{ct}}$ values became much higher. For instance, at $48 \mathrm{~h}$ immersion time, $R_{\mathrm{ct}}$ was 6.2 times greater at the concentration of $75 \mathrm{ppm}$ and 12.9 times as great at $100 \mathrm{ppm}$ propolis compared to the blank solution. These results show that the charge transfer process was strongly inhibited by propolis, especially when its concentration exceeded $50 \mathrm{ppm}$ and at prolonged immersion. The $C_{\mathrm{dl}}$ values significantly decreased in the presence of the inhibitor, as illustrated in Fig. $5 \mathrm{~b}$. At the early stages of immersion, the $C_{\mathrm{dl}}$ was about 75.2 $\mu \mathrm{F} \mathrm{cm}{ }^{-2}$ in the blank solution, whereas it reached values of $8.36 \mu \mathrm{F} \mathrm{cm}^{-2}$ and $1.96 \mu \mathrm{F} \mathrm{cm} \mathrm{cm}^{-2}$ in presence of propolis at concentrations of $75 \mathrm{ppm}$ and $100 \mathrm{ppm}$, respectively. As the time elapsed, a progressive decay of the $C \mathrm{dl}$ values occurred within the first $12 \mathrm{~h}$ of exposure in inhibitor-containing solutions and then, the $C \mathrm{dl}$ values remained almost constant throughout the rest of the measurements. Such small values of $C_{\mathrm{dl}}$ are associated with the presence of a protective layer on the bronze surface, leading to a smaller corroding area directly in contact with the electrolyte. This layer is likely to be formed by the adsorption of the main constituents of propolis on bronze surface, through the oxygen atoms in their functional groups (i.e. O-H, $\mathrm{C}-\mathrm{OH}, \mathrm{C}=\mathrm{O}$ ) and the aromatic rings, which have been evidenced by FT-IR spectra.

As mentioned before, the $R_{\mathrm{F}}-C_{\mathrm{F}}$ time constant might be ascribed to a reversible redox process involving the surface species accumulated during the corrosion process, in accordance with a mechanism previously reported [45] and based on the following reactions:

$$
\begin{aligned}
& \mathrm{Cu} \leftrightarrow \mathrm{Cu}(\mathrm{I})_{\mathrm{ad}}+\mathrm{e}^{-} \\
& \mathrm{Cu}(\mathrm{I})_{\mathrm{ad}} \rightarrow \mathrm{Cu}(\mathrm{II})+\mathrm{e}^{-}
\end{aligned}
$$

In the blank solution, the $C_{F}$ values laid in the range of a few $\mathrm{mF} \mathrm{cm}^{-2}$ at the beginning of immersion (Fig. 5d), and then slightly decreased beyond this period, likely due to decreased reactivity of the corrosion products with time. Much smaller values of $C_{\mathrm{F}}$ were obtained in the presence of propolis at concentrations higher than $50 \mathrm{ppm}$. Simultaneously, the faradaic resistances became greater in the presence of propolis and their values progressively increased with immersion time (Fig. 5c). The maximum values of $R_{\mathrm{F}}$ were attained in solutions containing $100 \mathrm{ppm}$ propolis with independence of the exposure period, while at this concentration, $C_{\mathrm{F}}$ attained the lowest values. Accordingly, it was assumed that the adsorption of the propolis' components on the bronze surface might decrease the amount of cuprous ions available in the redox process taking place on the electrode surface. In other terms, the adsorbed molecules hindered to some extent the formation of corrosion products (i.e. stable $\mathrm{Cu}_{2} \mathrm{O}$ ) on the electrode and made the reactivity of the bronze surface more homogeneous, providing an enhanced 
metallic protection. This correlates with the absence of the corrosion products on SEM and AFM micrographs obtained in the presence of propolis (see below).

It was demonstrated [47] that in the presence of redox processes taking place on the metallic surface, the polarization resistance, $R_{\mathrm{p}}$ and not the charge transfer resistance, is the parameter most closely correlated with the corrosion rate. The $R_{\mathrm{p}}$ values, calculated as $R_{\mathrm{ct}}+R_{\mathrm{F}}$, were used to determine the propolis inhibition efficiency, $z$, in accordance with following equation:

$$
z(\%)=\frac{R_{p}-R_{p}^{0}}{R_{p}}
$$

where $R_{p}$ and $R_{p}^{0}$ are the polarization resistances in solution with and without propolis, respectively. The variations of $R_{\mathrm{p}}$ and $z$ values with respect to immersion time, in the absence and in the presence of propolis at different concentrations, are illustrated graphically in Fig. 6.

As expected, the $R_{p}$ values increased in propolis-containing solutions, and this effect was more pronounced as the inhibitor concentration increased up to $100 \mathrm{ppm}$ and, then slightly decreased (Fig. 6a). At the initial immersion, the inhibition efficiency, $z$ reached values of 66.1\%, 82.03\% and 77.8\% for propolis concentrations of 75, 100 and 500 ppm, respectively. As the exposure time increased up to about $12 \mathrm{~h}$, the $z$ values progressively increased, suggesting the formation of a highly protective layer on the bronze surface, which significantly reduces the chemical attacks on the metal. Beyond this period, except for the solution containing 50 ppm propolis, the inhibiting efficiency reached high values (> 95\%) which remained fairly constant afterwards (Fig. 6b), confirming the ability of propolis to offer lasting protection to bronze against corrosion.

In the investigated experimental conditions, the highest $z$ values in the range of $98.9 \%$ were obtained in the presence of 100 ppm propolis. Further increases in propolis concentration showed a slight decrease in its inhibiting performance, in agreement with the results obtained by polarisation measurements.

\subsection{Adsorption isotherm}

Generally, the inhibiting properties of the corrosion inhibitors are related to their ability to adsorb and to form a protective layer on the metallic surface. The nature of the interaction between the inhibitor and the metal surface can be explained by using adsorption isotherms [23]. For this purpose, the surface coverage, $\theta$ was calculated as a function of the inhibitor 
concentration, assuming that the inhibitor efficiency was mainly due to the blocking effect of the adsorbed species on the bronze electrode, and hence $z=100 \times \theta$.

In order to acquire a better understanding of the adsorption mode of the propolis components on bronze surface, the surface coverage values obtained from the EIS measurements were tested with different adsorption isotherms, including Langmuir, Frumkin, and Temkin isotherms. The best fit as adjudged from Chi-square $\left(r^{2}\right)$ value was provided by the Langmuir adsorption isotherm that can be expressed as follows:

$$
\frac{C_{I n h}}{\theta}=\frac{1}{K}+C_{I n h}
$$

where: Inh $_{\text {is }}$ the propolis concentration, and $K$ is the adsorption equilibrium constant.

As shown in Fig. 7, the plot of $\frac{C_{I n h}}{\theta}$ versus $C_{\text {Inh }}$ yielded a straight line with nearly unity slope, confirming that the inhibitor adsorption on bronze obeys the Langmuir isotherm. It indicates that the adsorbing propolis' components occupy typical adsorption sites at the bronze/solution interface. Although Langmuir isotherm is based on the assumption that all the adsorption sites are equivalent and the molecules binding occurs independently from nearby sites being occupied or not, this might not be true in the case of propolis since it contains various organic molecules having polar atoms or functional groups from heterocyclic compounds which might interact one another. A similar situation was noticed by Faustin et al. [48] in the case of the corrosion inhibition of C38 steel by alkaloids extract of Geissospermum leave. Consequently, the discussion of the adsorption isotherm behaviour in terms of standard free energy of adsorption is not possible when using natural products as corrosion inhibitors since their molecular weight is unknown [48].

\subsection{SVET imaging}

SVET senses potential gradients in the electrolyte phase in direct contact with a sample originating from ionic fluxes of species involved in chemical and electrochemical processes at the surface of the material or in its close proximity. By rastering the surface at a constant height, spatially-resolved maps of the ionic currents were obtained as shown in Fig. 8a and b for a bronze sample immersed in $0.2 \mathrm{~g} \mathrm{~L}^{-1} \mathrm{Na}_{2} \mathrm{SO}_{4}+0.2 \mathrm{~g} \mathrm{~L}^{-1} \mathrm{NaHCO}_{3}$ (pH 5) up to $12 \mathrm{~h}$. Positive currents correspond to the ionic flow related to anodic sites, whereas the ionic flux from the cathodic sites appears as negative currents. As shown in the micrograph of Fig. 8c, that was taken with the videocamera attached to the SVET assembly after $12 \mathrm{~h}$ exposure to the test electrolyte, the bronze circular surface is located at the center of the image. Furthermore, the 
corrosive attack was observed to be mostly localized at the lower part of the exposed metal surface in the micrograph, with the observation of a corroded area where the metal dissolved preferentially, and a certain amount of corrosion products were deposited. Activation of the surface was higher around $6 \mathrm{~h}$ of exposure, with a small anodic region at the bottom, whereas the rest of the exposed metal actually behaved as a cathode for the electroreduction of oxygen (see Fig. 8a). A slightly smaller corrosion activity was observed at longer exposures, possibly due to partial blockage of the anodic site by the precipitation of corrosion products (Fig. 8b). After the sample was retrieved from the test solution, its surface was observed under the microscope to discard crevice formation. In this way, the electrochemical activity recorded in the SVET maps could be solely associated to the corrosion processes.

A completely different situation was imaged by SVET when the experiment was performed in the test electrolyte containing $100 \mathrm{ppm}$ of propolis as shown by the map recorded after 12 h that is given in Fig. 8d. Extremely low current density values were recorded, well around the background noise level of the technique, thus evidencing a practically complete inhibition of the corrosion process. The complete exposed surface behaved homogeneously, effectively protecting the metal from the onset of the localized corrosion microcells that were established in the test electrolyte in the absence of propolis (cf. Fig. 8a). Subsequently, the electrolyte was exchanged inside the electrochemical cell, as to expose the inhibitor-treated surface to the test electrolyte without inhibitor. Despite the removal of the inhibitor from the test electrolyte, the SVET maps recorded during $12 \mathrm{~h}$ exposure were also featureless (see Fig. 8e), confirming that the adsorbed film formed on bronze by propolis after $12 \mathrm{~h}$ was very adherent and continued protecting the metal even when propolis is not present in the electrolyte. These observations are confirmed by the micrograph shown in Fig. 8f, that was recorded for a bronze sample after $12 \mathrm{~h}$ exposure in the text electrolyte containing $100 \mathrm{ppm}$ propolis, followed by further $12 \mathrm{~h}$ to the inhibitor-free test electrolyte. No signs of corrosion were seen in the micrograph.

These observations are complementary to the information gathered using conventional electrochemical techniques, and would be consistent with the formation of a thicker and more protective patina layer promoted by propolis, as previously proposed on the basis of EIS data.

\subsection{SEM-EDX analysis}

Surface analysis was carried out by SEM-EDX technique in order to evaluate the surface morphology of the bronze samples in weakly acidic solution. SEM micrographs and the corresponding EDX spectra of bronze substrate after $48 \mathrm{~h}$ immersion in $0.2 \mathrm{~g} \mathrm{~L}^{-1} \mathrm{Na}_{2} \mathrm{SO}_{4}+0.2$ 
$\mathrm{g} \mathrm{L}^{-1} \mathrm{NaHCO}_{3}$ solution ( $\mathrm{pH}$ ) in the absence and presence of $100 \mathrm{ppm}$ propolis are shown in Fig. 9.

In absence of propolis, SEM micrograph revealed a severe corrosive attack of the bronze surface by the solution (Fig. 9a). The EDX spectrum reported in Fig. 9a' shows the characteristic peaks of the specimen and a marked presence of oxygen atoms, along with sulphur atoms.

A totally different situation was observed in the presence of $100 \mathrm{ppm}$ propolis. As shown in Fig. 9b, the bronze sample appeared to be smooth and without any visible traces of corrosion products, due to the formation of a protective inhibitor layer on the metallic surface, which retarded the dissolution process. The results were supported by EDX data revealing a very low content of oxygen species and no traces of sulphur on the bronze surface exposed to propolis-containing solution (Fig. 9b'). These results confirmed the high inhibiting efficiency of propolis at this concentration and corroborates those supplied by electrochemical techniques.

\subsection{AFM examination}

The topography of a bronze sample after abrasion and polishing pre-treatments was monitored by AFM and it is shown in Fig. 10a and c. Despite the mirror finish, the grinding directions were observed at the lower magnification (Fig. 10a), whereas greater magnification showed a rather homogeneous although somewhat rugged surface of $31.8 \mathrm{~nm}$ average roughness (Table 2 and Fig. 10e). Topographical changes were produced at the surface as result of propolis adsorption as shown in Figs. 10b and d. Deposition of a surface layer produced surface smoothing, where grinding and polishing lines were less noticeable even at the lower magnification. Surface smoothing was more evident from inspection of the AFM image in Fig. $10 \mathrm{~d}$ and the line profile of Fig. 10f, leading to a significant diminution of the average roughness down to $23.4 \mathrm{~nm}$ (Table 2). Therefore, a compact and homogeneous surface layer was formed as result of propolis interaction with bronze.

\subsection{Chemical compounds identified in the propolis}

Total phenolic content of the studied 1\% propolis solution presented $284.56 \pm 5.8 \mathrm{mg}$ $\mathrm{mL}^{-1}$ total polyphenols and $267.54 \mathrm{mg} \mathrm{mL}^{-1}$ flavone/flavonol, as determined by spectrophotometric measurements.

The determination of the phenolic acids and flavonoid compounds from the propolis solution was carried out by HPLC-DAD. The individual phenolic acids and flavonoids identified in the studied propolis solution are presented in Fig. 11 and Table 3. 
The analysed propolis solution was rich in polyphenolic substances, mainly phenolic acids and flavonoids. Four phenolic acids were identified and quantified (p-oOH benzoic, caffeic, ferulic and t-cinnamic acids), nine flavonoids (naringenin, quercetin, apigenin, kaempherol, kaempherol-3 rhamnosid, pinocembrin, chrysin, galangin and pinostrobin) and also vanillin. As it can be seen in Table 3, the main components of the propolis were: pinostrobin (225.77 $\mathrm{mg} \mathrm{mL}^{-1}$ ), trans-cinnamic acid (156.48 $\mathrm{mg} \mathrm{mL}^{-1}$ ), galangin $(139.11 \mathrm{mg}$ $\mathrm{mL}^{-1}$ ) and pinocembrin (130.74 $\left.\mathrm{mg} \mathrm{mL}^{-1}\right)$. High amounts of pinocembrin, chrysin, galangin and tectochrysin were previously reported in Chinese propolis [49-50], in accordance with our results. It should be also mentioned that the propolis samples from different or even the same regions of China may differ in their composition because of the local distributions of plants of many kinds. Therefore, it is difficult to identify the specific floral origin of a given propolis, but all samples present more or less the same pattern regarding the polyphenolic content.

The chemical molecular structures of the predominant compounds identified in the studied propolis are presented in Fig. 12.

As expected, the most abundant compounds identified in the propolis sample contained oxygen atoms with lone electron pairs and aromatic rings with delocalized electrons, which enabled them to adsorb on the metallic surface forming protective layers, which retarded the corrosion process.

\section{Conclusions}

The anticorrosive properties of natural propolis on bronze were investigated in $0.2 \mathrm{~g} \mathrm{~L}^{-1}$ $\mathrm{Na}_{2} \mathrm{SO}_{4}+0.2 \mathrm{~g} \mathrm{~L}^{-1} \mathrm{NaHCO}_{3}$ solution ( $\mathrm{pH}$ 5) using electrochemical methods (Tafel extrapolation, electrochemical impedance spectroscopy and scanning vibrating electrode technique) and surface characterization (SEM-EDX and AFM) techniques. Based on the results obtained in the present research, the following conclusions may be drawn:

(1) Propolis exhibits good inhibiting properties for bronze corrosion in weakly acidic solution containing $\mathrm{Na}_{2} \mathrm{SO}_{4}$ and $\mathrm{NaHCO}_{3}$ at $\mathrm{pH}$ 5; its inhibition efficiency increases with the immersion time and with increasing the propolis concentrations up to an optimum value of 100 ppm.

(2) Potentiodynamic polarization measurements reveal that propolis might be classified as a mixed-type inhibitor.

(3) EIS measurements proved that a highly protective effect is obtained in the presence of propolis after several hours of immersion and it remains stable during time. In the 
investigated experimental condition, the maximum inhibiting efficiency in the range of $98.9 \%$ was obtained by addition of 100 ppm propolis, after about $12 \mathrm{~h}$ of exposure to inhibitorcontaining electrolyte. Further increases in the propolis concentration produces a small decrease in its inhibiting performance, in agreement with the results obtained by polarisation measurements.

(4) SVET measurements evidenced that bronze corrosion is greatly reduced in the presence of propolis. A rather homogeneous coverage of the exposed metal surface is thus obtained that effectively protects the metal from the localized formation of corrosion microcells. The protective effect produced to bronze by propolis during $12 \mathrm{~h}$ treatment, led to the formation of a surface layer that continued offering protection to the metal even after removal of the inhibitor from the test electrolyte.

(5) The inhibiting effect of propolis on bronze corrosion is likely due to the adsorption of the various phenolic compounds present in the propolis, through the oxygen atoms in their functional groups and the aromatic rings, which have been evidenced by the FT-IR spectra. The adsorption of the propolis' components on bronze surface obeys Langmuir adsorption isotherm model.

(6) Results of the surface analysis performed by SEM-EDX and AFM confirms that propolis is able to retard the bronze corrosion by the formation of a compact and homogeneous surface layer on the metallic surface.

In summary, it might be assessed that propolis appears as a promising corrosion inhibitor for bronze in weakly acidic solution, both by its effectiveness and the environmentally-friendly properties. Although HPLC analysis identified the most abundant compounds present in the propolis sample, due to its complex chemical composition, it is difficult to assign the inhibitive effectiveness to a specific constituent. Further experiments are required to explain the role of the various compounds identified in propolis and their inhibition mechanisms.

\section{References}

[1] M.M. Antonijevic, M.B. Petrovic, Copper corrosion inhibitors. A review, Int. J. Electrochem. Sci. 3 (2008) 1-28.

[2] T. Ramde, S. Rossi, C. Zanella, Inhibition of the Cu65/Zn35 brass corrosion by natural extract of Camellia sinensis, Appl. Surf. Sci. 307 (2014) 209-216. 
[3] S.M.A. Quraishi, Electrochemical and theoretical investigation of triazole derivatives on corrosion inhibition behavior of copper in hydrochloric acid medium, Corros. Sci. 70 (2013) 161-169.

[4] G. Žerjav, I. Milošev, Protection of copper against corrosion in simulated urban rain by the combined action of benzotriazole, 2-mercaptobenzimidazole and stearic acid, Corros. Sci. 98 (2015) 180-191.

[5] S. Varvara, L. Muresan, K. Rahmouni, H. Takenouti, Evaluation of some nontoxic thiadiazole derivatives as bronze corrosion inhibitors in aqueous solution, Corros. Sci. 50 (2008) 2596-2604.

[6] S. Varvara, R. Bostan, L. Găină, L.M. Muresan, Thiadiazole derivatives as inhibitors for acidic media corrosion of artificially patinated bronze, Mater. Corr. 65 (2014) 1202-1214.

[7] H. Tian, W. Li, K. Cao, B. Hou, Potent inhibition of copper corrosion in neutral chloride media by novel non-toxic thiadiazole derivatives, Corros. Sci. 73 (2013) 281-291.

[8] M.B. Petrović Mihajlović, M.B. Radovanović, Ž.Z. Tasić, M.M. Antonijević, Imidazole based compounds as copper corrosion inhibitors in seawater, J. Mol. Liq. 225 (2017) 127-136. [9] I. Milošev, N. Kovačević, J. Kovač, A. Kokalj, The roles of mercapto, benzene and methyl groups in the corrosion inhibition of imidazoles on copper: I. Experimental characterization, Corros. Sci. 98 (2015) 107-118.

[10] H. Otmacic Curkovic, E. Stupnišek-Lisac, H. Takenouti, The influence of pH value on the efficiency of imidazole based corrosion inhibitors of copper, Corros. Sci. 52 (2010) 398-405.

[11] H. Saifi, M.C. Bernard, S. Joiret, K. Rahmouni, H. Takenouti, B. Talhi, Corrosion inhibitive action of cysteine on Cu-30Ni alloy in aerated $0.5 \mathrm{M} \mathrm{H}_{2} \mathrm{SO}_{4}$, Mater. Chem. Phys. 120 (2010) 661-669.

[12] D.Q. Zhang, Q.R. Cai, X.M. He, L.X. Gao, G.D. Zhou, Inhibition effect of some amino acids on copper corrosion in HCl solution, Mater. Chem. Phys. 112 (2008) 353-358.

[13] S. Varvara, M. Popa, L.M. Muresan, Corrosion inhibition of bronze by amino acids in aqueous acidic solutions, Studia Univ. Babes-Bolyai Chemia 54 (2009) 235-246.

[14] R. Bostan, S. Varvara, L. Găină, L.M. Mureşan, Evaluation of some phenothiazine derivatives as corrosion inhibitors for bronze in weakly acidic solution, Corros. Sci. 63 (2012) 275-286.

[15] M. Behpour, S.M. Ghoreishi, M. Salavati-Niasari, B. Ebrahimi, Evaluating two new synthesized S-N Schiff bases on the corrosion of copper in 15\% hydrochloric acid, Mater. Chem. Phys. 107 (2008) 153-157. 
[16] P. Thanapackiam, S. Rameshkumar, S.S. Subramanian, K. Mallaiya, Electrochemical evaluation of inhibition efficiency of ciprofloxacin on the corrosion of copper in acid media, Mater. Chem. Phys. 174 (2016) 129-137.

[17] I. Rotaru, S. Varvara, L. Gaina, L.M. Muresan, Antibacterial drugs as corrosion inhibitors for bronze surfaces in acidic solutions, Appl. Surf. Sci. 321 (2014) 188-196.

[18] J.J. Fu, S.N. Li, L.H. Cao, Y. Wang, L.H. Yan, L.D. Lu, L-Tryptophan as green corrosion inhibitor for low carbon steel in hydrochloric acid solution, J. Mater. Sci. 45 (2010) 979-986.

[19] S.A. Umoren, M.M. Solomon, Effect of halide ions on the corrosion inhibition efficiency of different organic species - A review, J. Ind. Eng. Chem. 21 (2015) 81-100.

[20] F.S. de Souza, C. Giacomelli, R.S. Gonçalves, A. Spinelli, Egyptian licorice extract as a green corrosion inhibitor for copper in hydrochloric acid solution, J. Ind. Eng. Chem. 22 (2015) 384-389.

[21] K. Krishnaveni, J. Ravichandran, Influence of aqueous extract of leaves of Morinda tinctoria on copper corrosion in HCl medium, J. Electroanal. Chem. 735 (2014) 24-31.

[22] C. Rahal, M. Masmoudi, R. Abdelhedi, R. Sabot, M. Jeannin, M. Bouaziz, P. Refait, Olive leaf extract as natural corrosion inhibitor for pure copper in $0.5 \mathrm{M} \mathrm{NaCl}$ solution: A study by voltammetry around OCP, J. Electroanal. Chem. 769 (2016) 53-61.

[23] H. Gerengi, K. Schaefer, H.I. Sahin, Corrosion-inhibiting effect of Mimosa extract on brass-MM55 corrosion in $0.5 \mathrm{M} \mathrm{H}_{2} \mathrm{SO}_{4}$ acidic media, J. Ind. Eng. Chem. 18 (2012) 2204-2210. [24] R.M. Saleh, A.A. Ismall, A.A. El Hosary, Corrosion inhibition by naturally occurring Substances: VII. The effect of aqueous extracts of some leaves and fruit-peels on the corrosion of steel, Al, Zn and Cu in acids, Br. Corrosion J. 17 (1982) 131-135.

[25] E. Baran, A. Cakira, B. Yazicib, Inhibitory effect of Gentiana olivieri extracts on the corrosion of mild steel in $0.5 \mathrm{M} \mathrm{HCl}$ : Electrochemical and phytochemical evaluation, Arab. J. Chem. (2016), https://doi.org/10.1016/j.arabjc.2016.06.008.

[26] P.B. Raja, M.G. Sethuraman, Natural products as corrosion inhibitor for metals in corrosive media—a review, Mater. Lett. 62 (2008) 113-116.

[27] N. M’hiri, D. Veys-Renaux, E. Rocca, I. Ioannou, N.M. Boudhrioua, M. Ghoul, Corrosion inhibition of carbon steel in acidic medium by orange peel extract and its main antioxidant compounds, Corros. Sci. 102 (2016) 55-62.

[28] A.Y. El-Etre, Natural honey as corrosion inhibitor for metals and alloys. I. Copper in neutral aqueous solution, Corros. Sci. 40 (1998) 1845-1850.

[29] I. Radojcic, K. Berkovic, S. Kovac, J. Vorkapic-Furac, Natural honey and black radish juice as tin corrosion inhibitors, Corros. Sci. 50 (2008) 1498-1504. 
[30] W.B. Wan Nik, M.F. Zulkifli, R. Rosliza, M.J. Ghazali, K.F. Khaled, Potential of honey as corrosion inhibitor for aluminium alloy in seawater, World Appl. Sci. J. 14 (2011) 215-220. [31] A.Y. El-Etre, M. Abdallah, Natural honey as corrosion inhibitor for metals and alloys. II. C-steel in high saline water, Corros. Sci. 42 (2000) 731-738.

[32] A.O. Odiongenyi, I.S. Enengedi, I. Ibok, E.J. Ukpong, Inhibition of the corrosion of zinc in $0.1 \mathrm{M} \mathrm{HCl}$ by ethanol extract of honey, Int. J. Chem. Mater. Environ. Res. 2 (2015) 16-25. [33] R. Rosliza, W.B. Wan Nik, S. Izman, Y. Prawoto, Anti-corrosive properties of natural honey on Al-Mg-Si alloy in seawater, Curr. Appl. Phys.10 (2010) 923-929.

[34] L. Vrsalovic, S. Gudic, M. Kliskic, Salvia officinalis L. honey as corrosion inhibitor for CuNiFe in sodium chloride solution, Ind. J. Chem. Technol. 19 (2012) 96-102.

[35] F. Gapsari, R. Soenoko, A. Suprapto, W. Suprapto, Bee wax propolis extract as ecofriendly corrosion inhibitors for 304SS in sulfuric acid, Int. J. Corros. (2015) 1-10.

[36] A.S. Fouda, A. Hamdy Badr, Aqueous extract of propolis as corrosion inhibitor for carbon steel in aqueous solutions, Afr. J. Pure Appl. Chem. 7 (2013) 350-359.

[37] L.M.P. Dolabella, J.G. Oliveira, V. Lins, T. Matencio, W.L. Vasconcelos, Ethanol extract of propolis as a protective coating for mild steel in chloride media, J. Coat. Technol. Res. 13 (2016) 543-555.

[38] I. Gülçin, E. Bursal, M.H. Sehitoğlu, M. Bilsel, A.C. Gören, Polyphenol content and antioxidant activity of lyophilized aqueous extract of propolis from Erzurum, Turkey, Food Chem Toxicol, 48 (2010) 2227-2238.

[39] K.R. Markham, K.A. Mitchell, A.L. Wilkins, J.A. Daldy, Y. Lu, HPLC and GC-MS identification of the major organic constituents in New Zealand propolis, Phytochem. 42 (1996) 205-211.

[40] A.H. Banksnota, Y. Tezuka, S.H. Kadota, Recent progress in pharmacological research of propolis, Phytother. Res. 15 (2001) 561-571.

[41] E. Szliszka, Z.P. Czuba, M. Domino, B. Mazur, G. Zydowicz, W. Krol, Ethanolic extract of propolis (EEP) enhances the apoptosis - inducing potential of TRAIL in cancer cells, Molecules 14 (2009) 738-54.

[42] V.L. Singleton, R. Orthofer, R., R.M. Lamuela-Raventos, Analysis of total phenols and other oxidation substrates and antioxidants by means of Folin-Ciocalteu reagent, Methods Enzymol. 299 (1999) 152-178.

[43] M. Popova, V. Bankova, D. Butovska, V. Petkov, B. Nikolova-Damyanova, A.G. Sabatini, G.L. Marcazzan, S. Bogdanov, Validated methods for the quantification of biologically active constituents of poplar type propolis, Phytochem. Anal. 15 (2004) 235-240. 
[44] V. Arvouet-Grand, B. Vennat, A. Pourrat P. Legret, Standardisation d'un extrait de propolis et identification des principaux constituents, J. Pharm. Belg. 49 (1994) 462-468.

[45] K. Marusic, H. Otmacic Curkovic, H. Takenouti, Inhibiting effect of 4-methyl-1-ptolylimidazole to the corrosion of bronze patinated in sulphate medium, Electrochim. Acta 56 (2011) 7491-7502.

[46] I.D. Raistrick, J.R. MacDonald, D.R. Franceschetti, The electrical analogs of physical and chemical processes, in: J.R. MacDonald (Ed.), Impedance Spectroscopy Emphasizing Solid Materials and Systems, John Wiley \& Sons, New York, 1987, pp. 27-84.

[47] I. Epelboin, C. Gabrielli, M. Keddam, H. Takenouti, AC impedance measurements applied to corrosion studies and corrosion rate determination, in: F. Mansfeld, U. Bertocci (Eds.), Electrochemical Corrosion Testing, vol. STP 727, American Society for Testing and Materials, Philadelphia, PA, 1981, p. 150.

[48] M. Faustin, A. Maciuk, P. Salvin, C. Roos, M. Lebrini, Corrosion inhibition of C38 steel by alkaloids extract of Geissospermum leave in $1 \mathrm{M}$ hydrochloric acid: Electrochemical and phytochemical studies, Corros. Sci. 92 (2015) 287-300.

[49] M.R. Ahn, S. Kumazawa, Y. Usui, J. Nakamura, M. Matsuka, F. Zhu, T, Nakayama, Antioxidant activity and constituents of propolis collected in various areas of China, Food Chem. 101 (2007) 1383-1392.

[50] J. Zhou, Y. Li, J. Zhao, X. Xue, L. Wu, F. Chen, Geographical traceability of propolis by high-performance liquid chromatography fingerprints, Food Chem. 108 (2008) 749-759. 


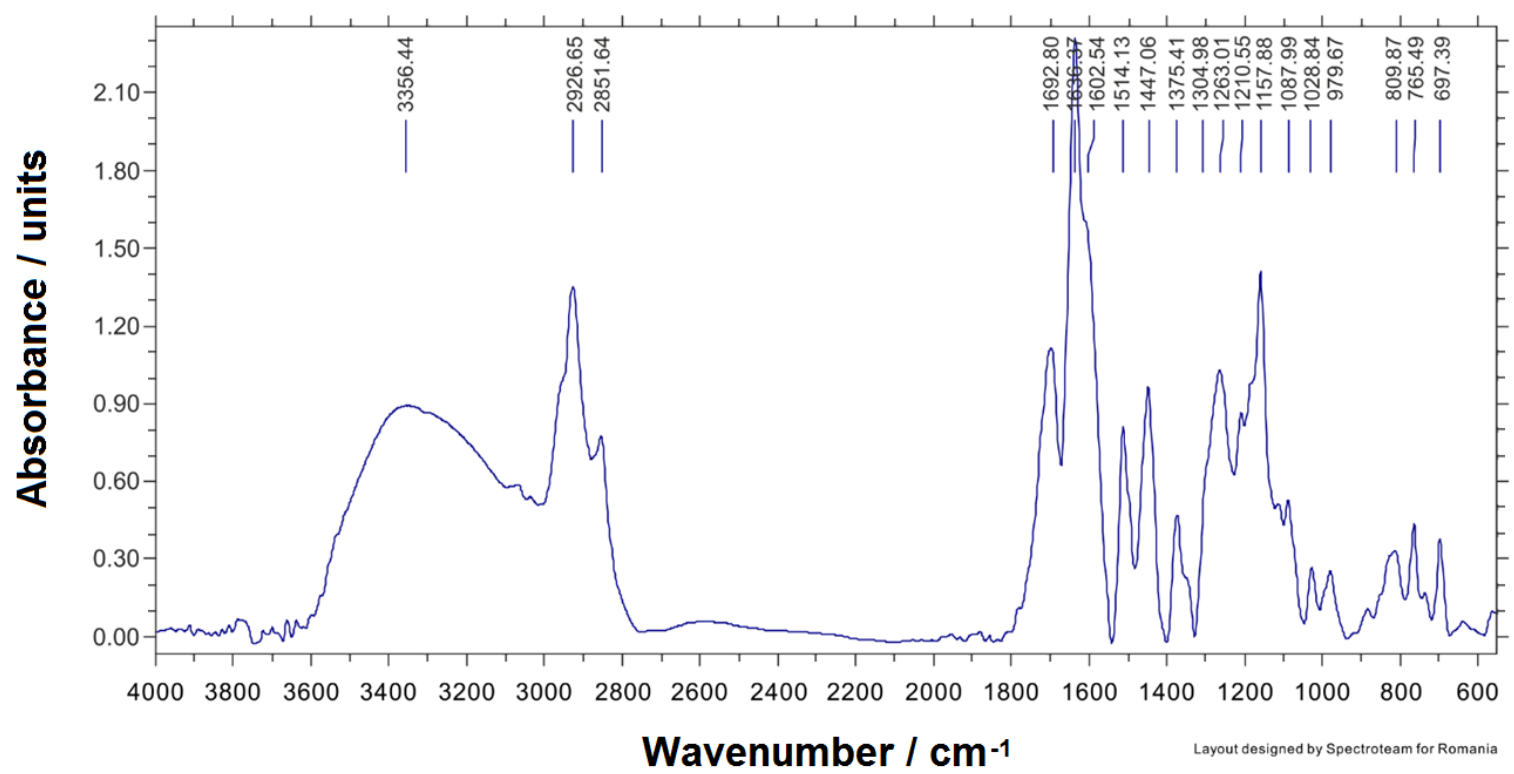

Fig. 1. FT-IR absorption spectrum of propolis recorded on $\mathrm{KBr}$ pellets.
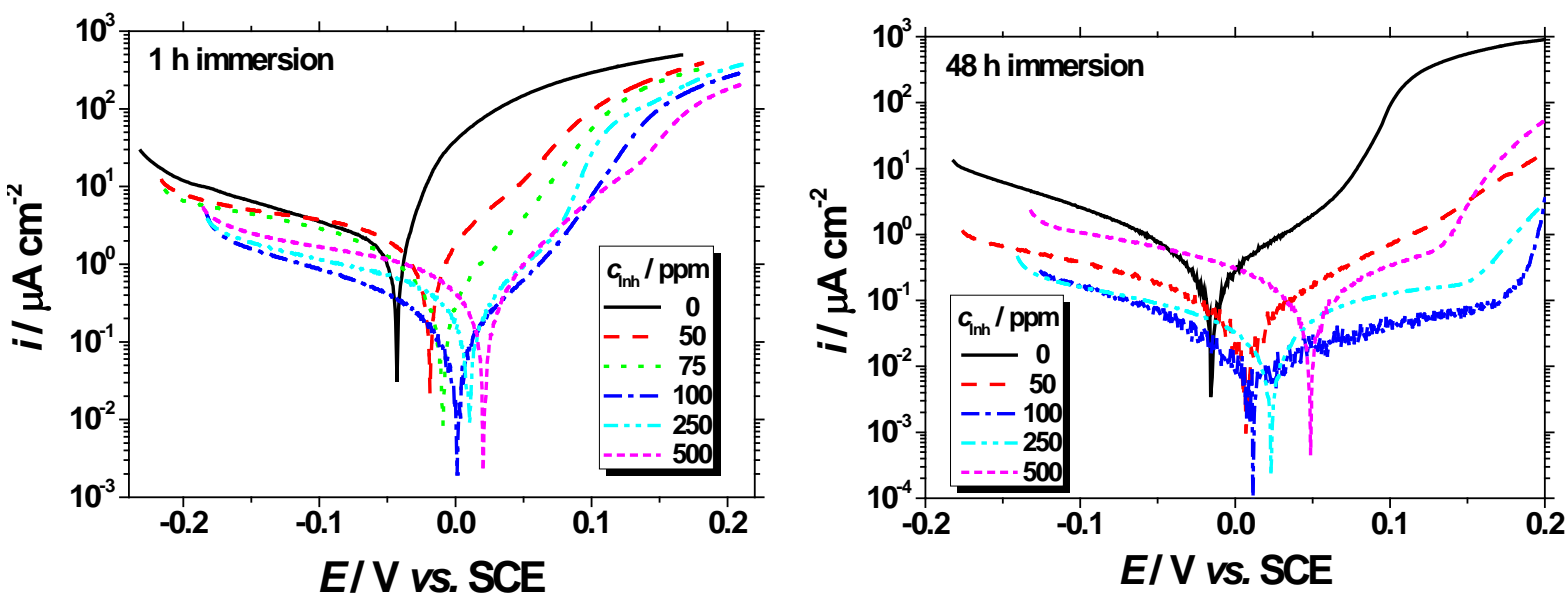

Fig. 2. Polarization curves of bronze after different exposure times in $0.2 \mathrm{~g} \mathrm{~L}^{-1} \mathrm{Na}_{2} \mathrm{SO}_{4}+0.2 \mathrm{~g}$ $\mathrm{L}^{-1} \mathrm{NaHCO}_{3}(\mathrm{pH}$ ) solution in the absence and in the presence of propolis at various concentrations (CInh). 

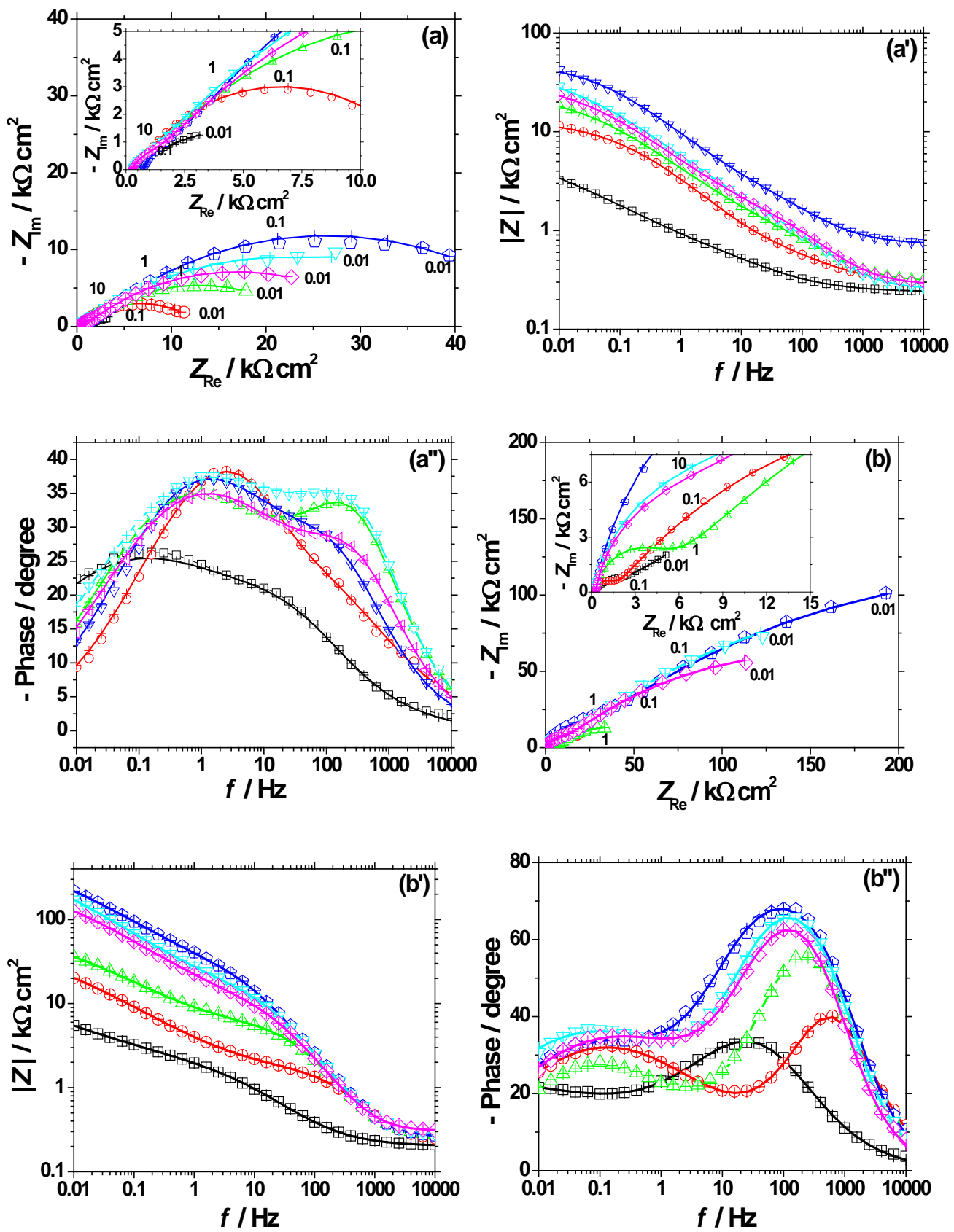

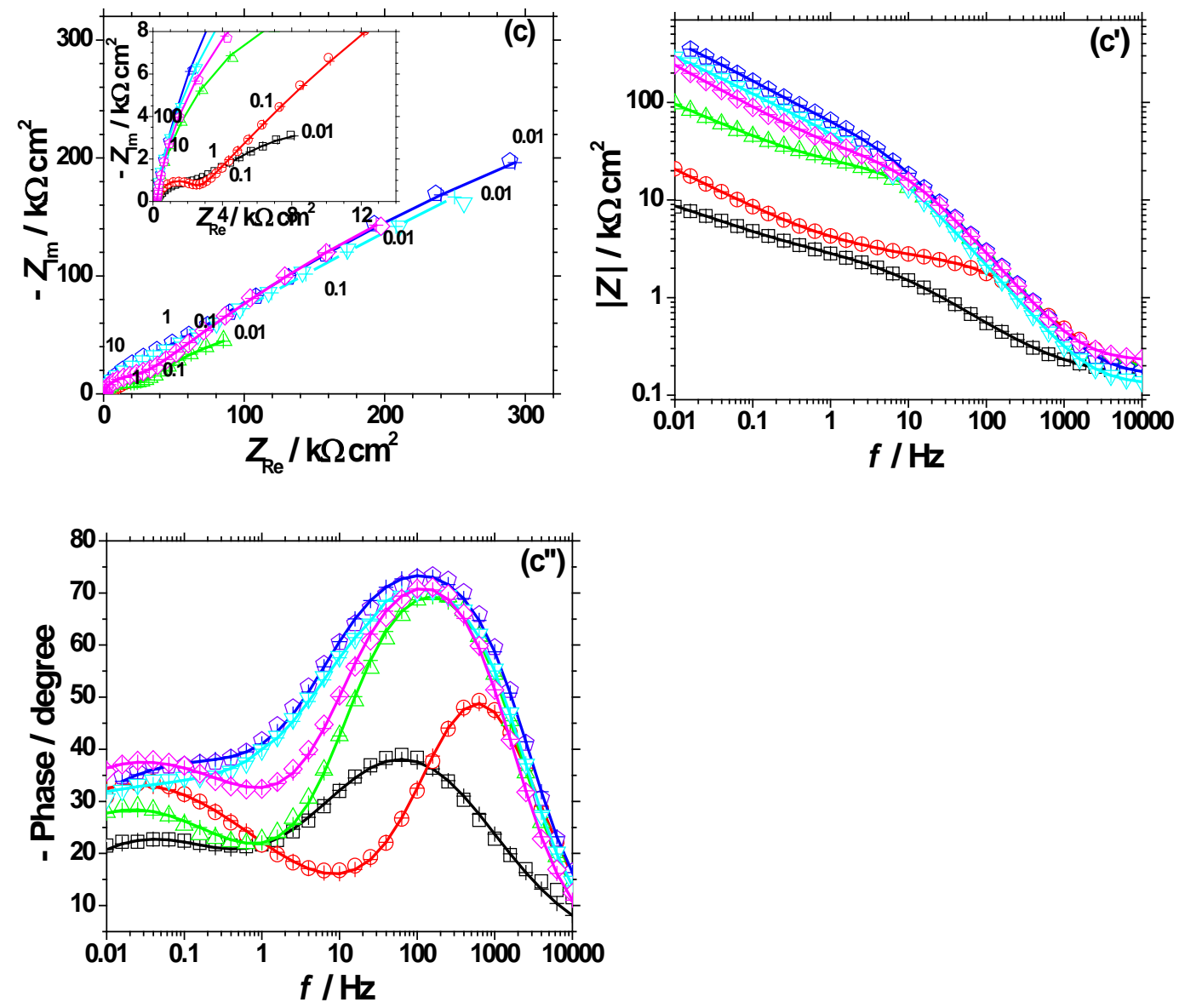

Fig. 3. Nyquist and Bode diagrams corresponding to bronze corrosion after exposure time for (a, a', a’') 1, (b, b’, b’') 12, and (c, c', c’') 48 h in 0.2 g L$^{-1} \mathrm{Na}_{2} \mathrm{SO}_{4}+0.2 \mathrm{~g} \mathrm{~L}^{-1} \mathrm{NaHCO}_{3}$ (pH 5) in the absence $(\square)$ and in the presence of propolis at different concentrations (ppm): ( $\odot$ ) 50; $(\triangle)$ 75, $(\triangle)$ 100, $(\nabla)$ 250, and $(\diamond)$ 500. Symbols: experimental data; dotted lines: fitting results. The numbers in the Nyquist diagrams (a, b, c) refer to frequency in $\mathrm{Hz}$.

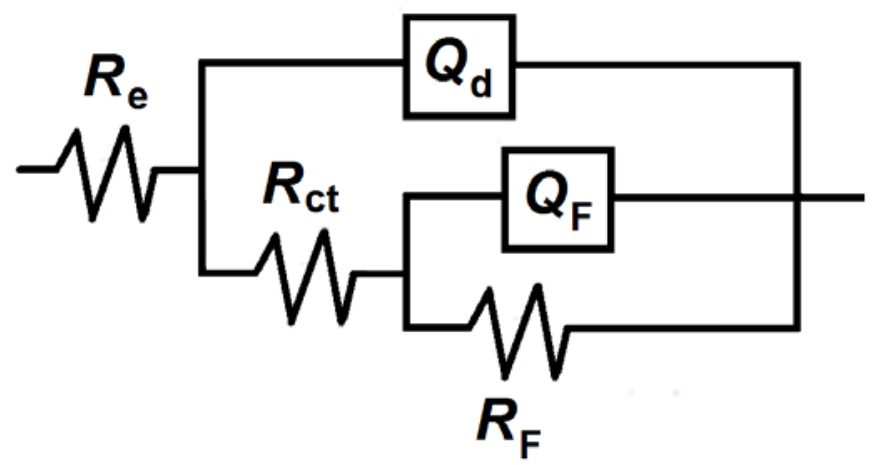

Fig. 4. Equivalent electrical circuit used for computer fitting of the experimental data. 

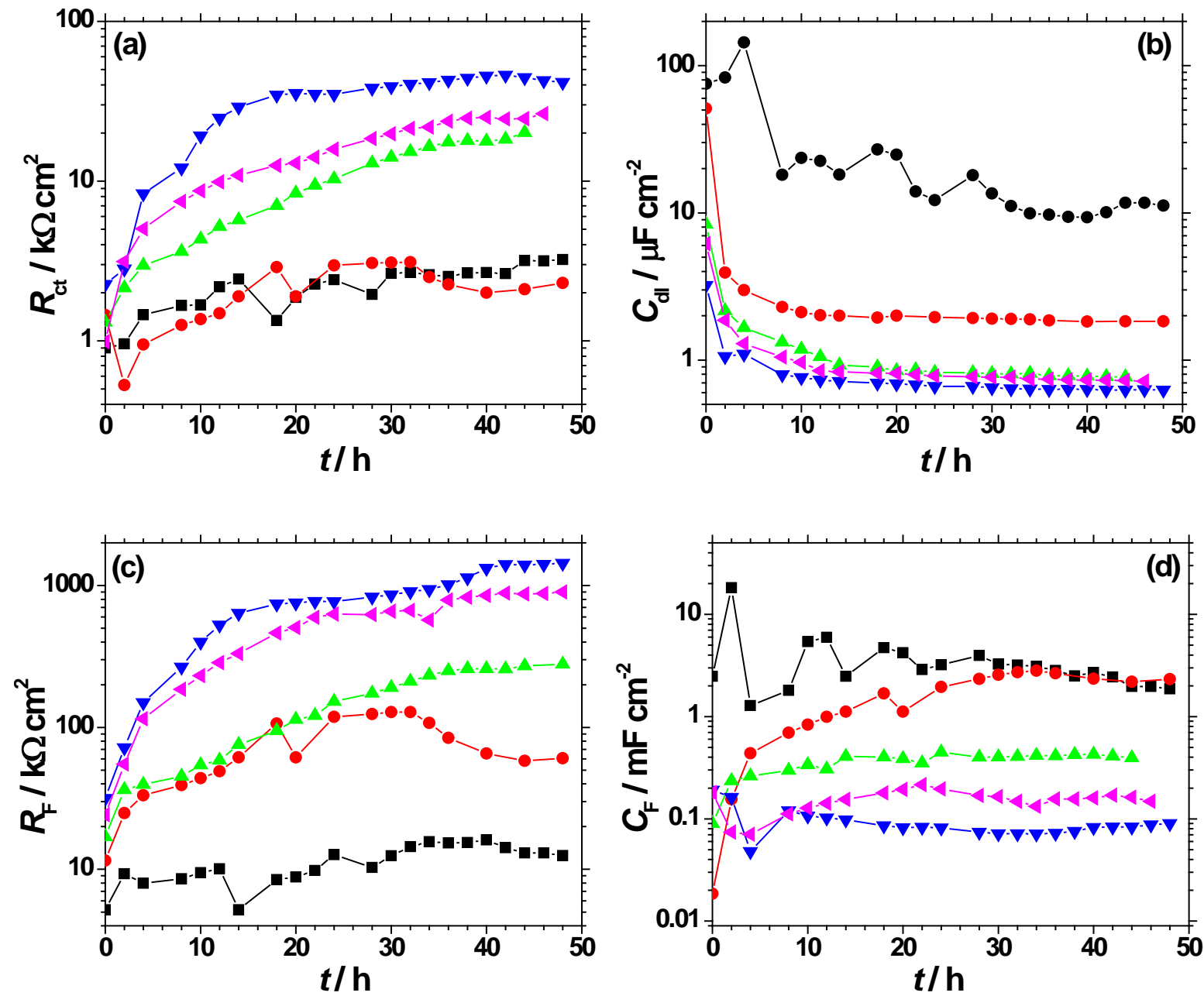

Fig. 5. Time evolution of the calculated $R$ - $C$ parameters during the bronze exposure in $0.2 \mathrm{~g} \mathrm{~L}^{-1}$ $\mathrm{Na}_{2} \mathrm{SO}_{4}+0.2 \mathrm{~g} \mathrm{~L}^{-1} \mathrm{NaHCO}_{3}(\mathrm{pH}$ ) in the ( - absence and in the presence of propolis, at different concentrations (ppm): $(\bullet)$ 50, $(\Delta)$ 75, ( $\boldsymbol{\nabla})$ 100, and $(<) 500$.
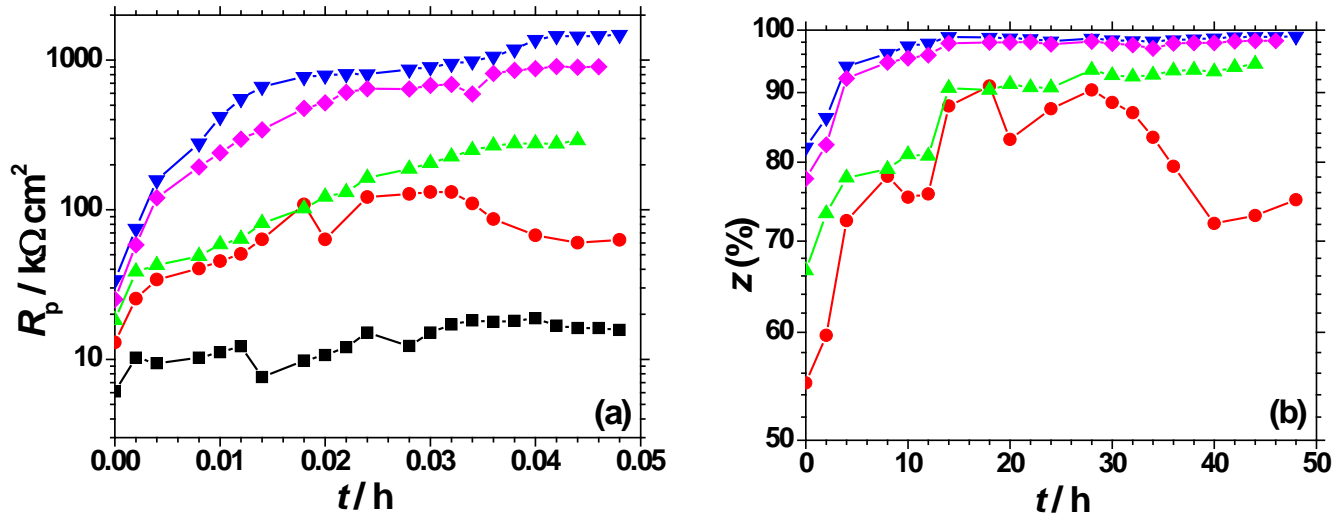

Fig. 6. Variation of polarization resistance (a) and inhibition efficiency (b) with respect to the immersion time in $0.2 \mathrm{~g} \mathrm{~L}^{-1} \mathrm{Na}_{2} \mathrm{SO}_{4}+0.2 \mathrm{~g} \mathrm{~L}^{-1} \mathrm{NaHCO}_{3}(\mathrm{pH}$ ) in the absence ( $\mathbf{a})$ and in the

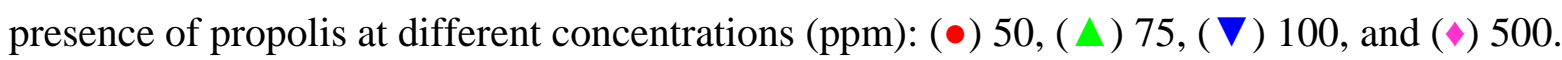




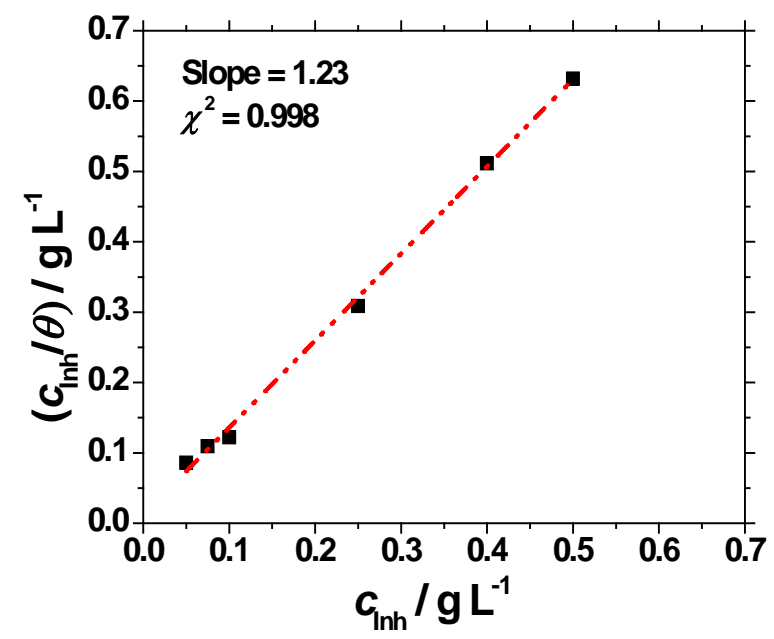

Fig. 7. Langmuir adsorption plot obtained from EIS for bronze corrosion in $0.2 \mathrm{~g} \mathrm{~L}^{-1} \mathrm{Na}_{2} \mathrm{SO}_{4}+$ $0.2 \mathrm{~g} \mathrm{~L}^{-1} \mathrm{NaHCO}_{3}$ ( $\mathrm{pH}$ ) solution containing different concentrations of propolis.
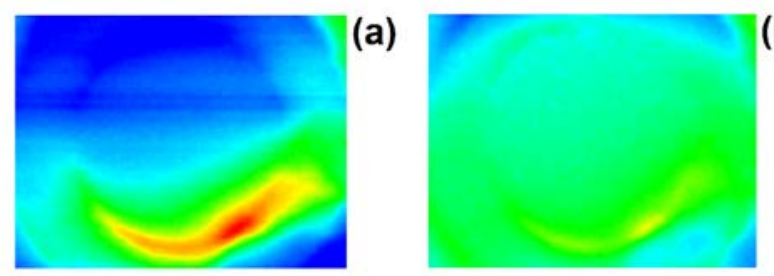

(b)

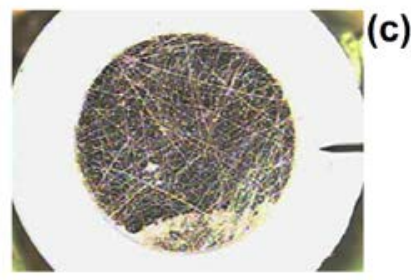

$j / \mu \mathrm{A} \mathrm{cm}-2$
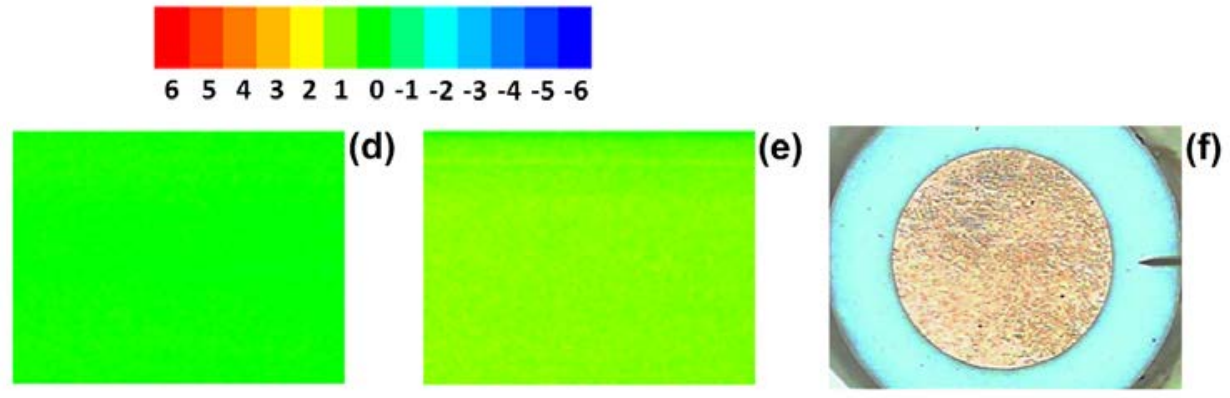

Fig. 8. SVET images and micrographs of a circular bronze sample (area, $28.27 \mathrm{~mm}^{2}$ ) immersed in $0.2 \mathrm{~g} \mathrm{~L}^{-1} \mathrm{Na}_{2} \mathrm{SO}_{4}+0.2 \mathrm{~g} \mathrm{~L}^{-1} \mathrm{NaHCO}_{3}(\mathrm{pH}$ ) either in the presence or in the absence of propolis. (a-c) Bronze sample non-treated with propolis; the maps were recorded after (a) 6 and (b) $12 \mathrm{~h}$ exposure to the test solution. Micrograph (c) was taken after recording the SVET map shown in (b). (d) Bronze sample immersed in $0.2 \mathrm{~g} \mathrm{~L}^{-1} \mathrm{Na}_{2} \mathrm{SO}_{4}+0.2 \mathrm{~g} \mathrm{~L}^{-1} \mathrm{NaHCO}_{3}+100 \mathrm{ppm}$ propolis (pH 5) for $12 \mathrm{~h}$. (e) SVET map recorded over the bronze sample of (d) after electrolyte replacement, and further exposure to $0.2 \mathrm{~g} \mathrm{~L}^{-1} \mathrm{Na}_{2} \mathrm{SO}_{4}+0.2 \mathrm{~g} \mathrm{~L}^{-1} \mathrm{NaHCO}_{3}$ (pH 5) for additional $12 \mathrm{~h}$. (f) Micrograph obtained after recording the SVET image in (e). The images represent $9750 \mu \mathrm{m} \times 5360 \mu \mathrm{m}$ in $X$ and $Y$ directions. 

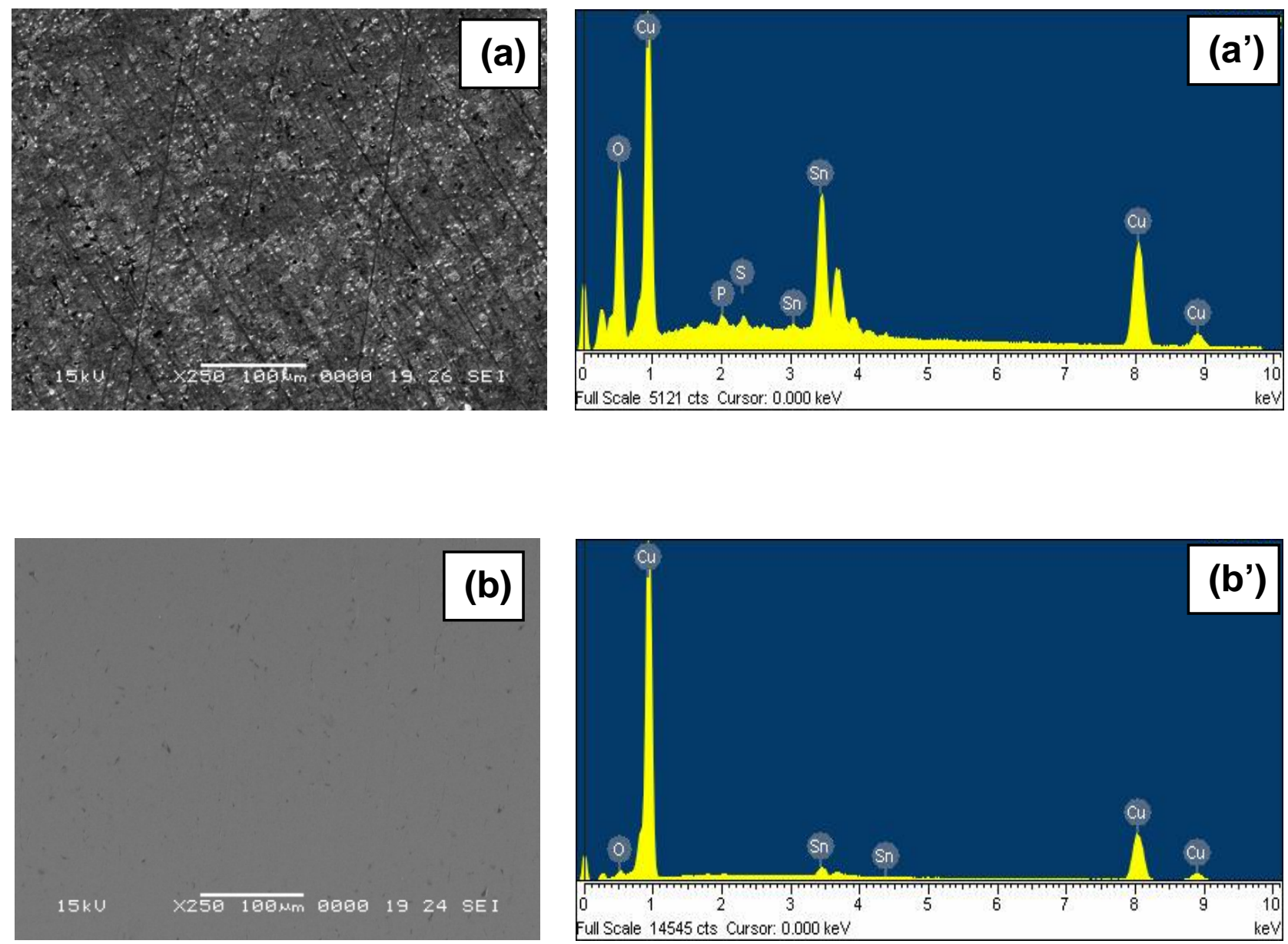

Fig. 9. SEM pictures and EDX spectra of bronze after $48 \mathrm{~h}$ exposure to $0.2 \mathrm{~g} \mathrm{~L}^{-1} \mathrm{Na}_{2} \mathrm{SO}_{4}+0.2$ $\mathrm{g} \mathrm{L}^{-1} \mathrm{NaHCO}_{3}$ solution (pH 5) in the absence (a, a'), and in the presence of $100 \mathrm{ppm}$ propolis (b, b’). 

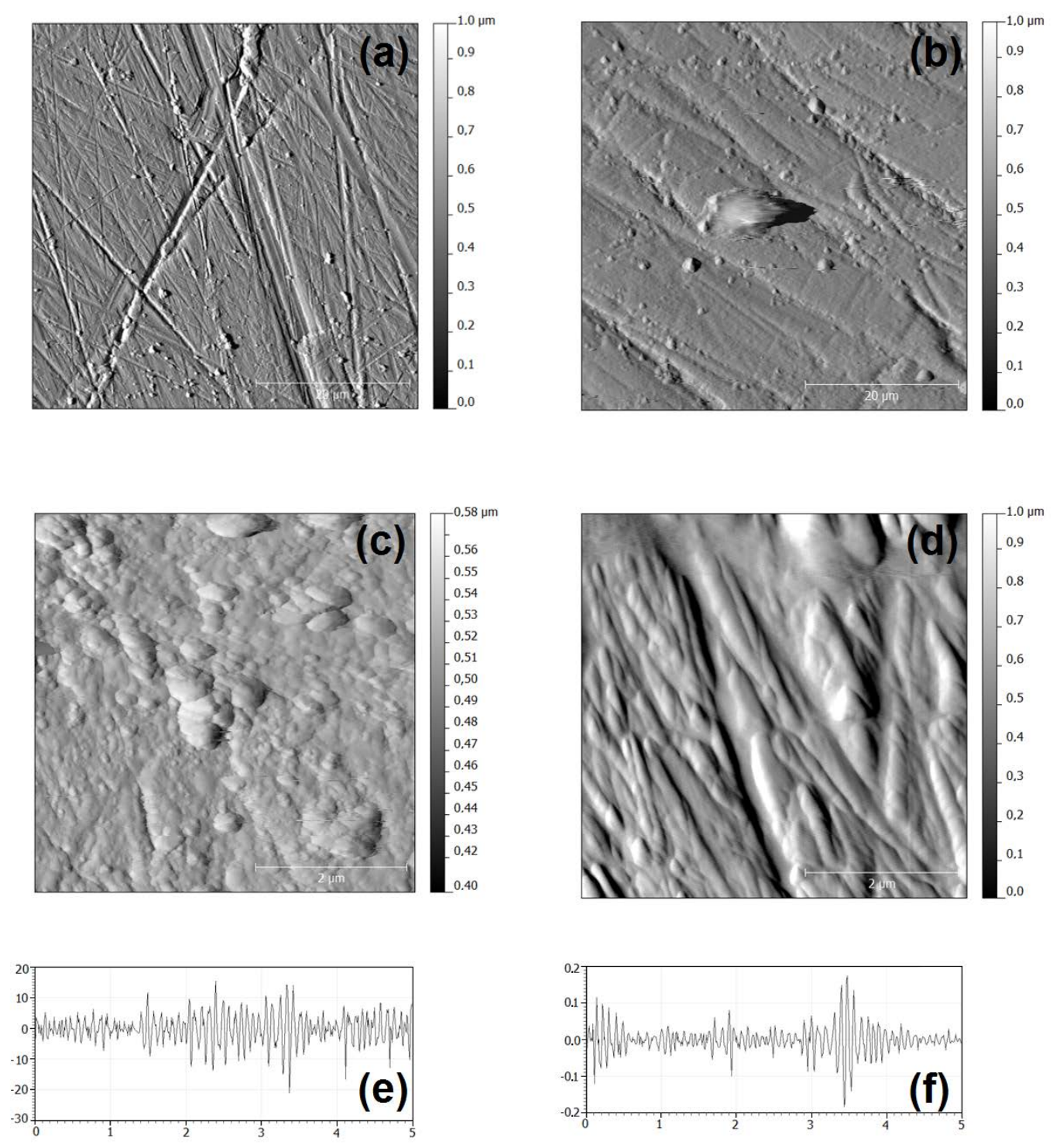

Fig. 10. AFM surface topography (a-d) and line profiles (e, f) for a bronze sample, before (a, c, e), and after $12 \mathrm{~h}$ exposure to $0.2 \mathrm{~g} \mathrm{~L}^{-1} \mathrm{Na}_{2} \mathrm{SO}_{4}+0.2 \mathrm{~g} \mathrm{~L}^{-1} \mathrm{NaHCO}_{3}$ solution ( $\mathrm{pH}$ ) in the presence of $100 \mathrm{ppm}$ propolis (b, d, f). 


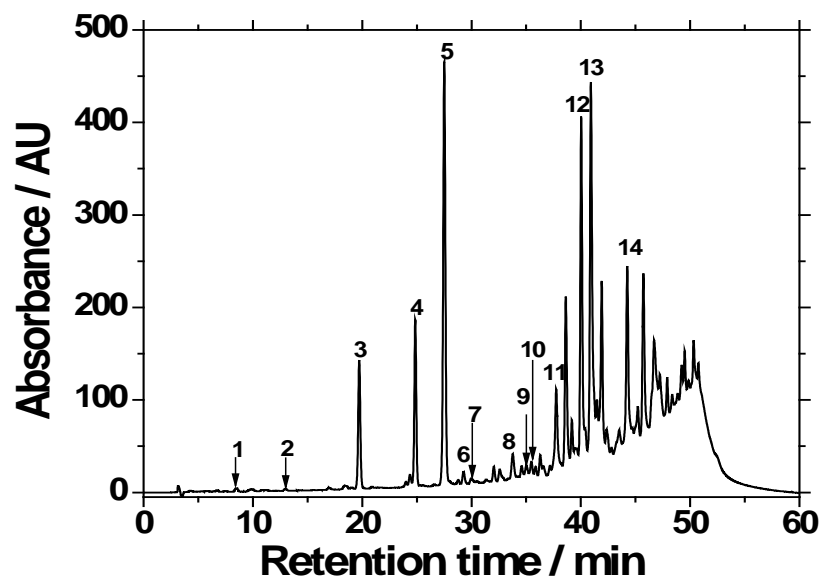

Fig. 11. HPLC chromatogram of $1 \%$ (w/v) propolis solution. 1. p-OH-benzoic acid; 2. Vanillin; 3. Caffeic acid; 4. Ferulic acid; 5. t-cinnamic acid; 6. Naringenin; 7.Quercetin; 8. Apigenin; 9. Kaempherol; 10. Kaempherol-3-rhamnosid; 11. Pinocembrin; 12. Chrysin; 13. Galangin; 14. Pinostrobin.<smiles>COc1cc(O)c2c(c1)OC(c1ccccc1)CC2=O</smiles>

pinostrobin<smiles>O=c1c(O)c(-c2ccccc2)oc2cc(O)cc(O)c12</smiles>

galangin<smiles>O=C(O)/C=C/c1ccccc1</smiles>

t-cinnamic acid<smiles>O=C1C[C@H](c2ccccc2)Oc2cc(O)cc(O)c21</smiles>

pinocembrin

Fig. 12. Chemical molecular structures of the most abundant compounds from the propolis sample. 
Table 1. Electrochemical corrosion parameters of bronze in $0.2 \mathrm{~g} \mathrm{~L}^{-1} \mathrm{Na}_{2} \mathrm{SO}_{4}+0.2 \mathrm{~g} \mathrm{~L}^{-1}$ $\mathrm{NaHCO}_{3}(\mathrm{pH}$ ) solution, in the absence and in the presence of various concentrations of propolis, determined at different immersion times

\begin{tabular}{|c|c|c|c|c|c|}
\hline $\begin{array}{l}C_{\text {Inh }} / \\
\text { ppm }\end{array}$ & $\begin{array}{c}E_{\text {corr }} / \\
\text { mV vs. SCE }\end{array}$ & $\begin{array}{c}\boldsymbol{i}_{\text {corr }} / \\
\mu \mathrm{A} \mathrm{cm} \mathbf{c m}^{-2}\end{array}$ & $\begin{array}{c}\left|\beta_{\mathrm{c}}\right| / \\
\mathrm{mV} \operatorname{dec}^{-1}\end{array}$ & $\begin{array}{c}\beta_{\mathrm{a}} / \\
\mathrm{mV} \mathrm{dec}^{-1}\end{array}$ & $z(\%)$ \\
\hline \multicolumn{6}{|c|}{$1 \mathrm{~h}$ immersion } \\
\hline 0 & -42.90 & 2.00 & 186.8 & 34.4 & - \\
\hline 50 & -18.02 & 1.31 & 207.3 & 81.6 & 34.5 \\
\hline 75 & -9.03 & 0.57 & 110.5 & 70.5 & 71.5 \\
\hline 100 & 1.12 & 0.25 & 126.0 & 69.7 & 87.5 \\
\hline 250 & 10.36 & 0.33 & 167.5 & 69.4 & 83.5 \\
\hline 500 & 21.15 & 0.52 & 184.3 & 69.1 & 74.0 \\
\hline \multicolumn{6}{|c|}{$48 \mathrm{~h}$ immersion } \\
\hline 0 & -13.26 & 0.56 & 89.1 & 75.2 & - \\
\hline 50 & 7.55 & 0.16 & 168.6 & 109.8 & 71.4 \\
\hline 100 & 13.94 & 0.028 & 109.5 & 228.2 & 95.0 \\
\hline 250 & 23.23 & 0.043 & 143.7 & 122.3 & 92.3 \\
\hline 500 & 49.35 & 0.051 & 97.2 & 73.9 & 90.9 \\
\hline
\end{tabular}

Table 2. Surface roughness of pristine and propolis-treated bronze

\begin{tabular}{lcc}
\hline Sample & $\begin{array}{c}\text { Roughness } \\
\text { average, } \boldsymbol{R}_{\mathbf{a}} \\
/ \mathbf{~ m m}\end{array}$ & $\begin{array}{c}\text { Root mean } \\
\text { square } \\
\text { roughness, } \boldsymbol{R}_{\mathbf{q}} \\
/ \mathbf{~ n m ~}\end{array}$ \\
\hline Non-treated & 31.8 & 43.7 \\
Treated with propolis (100 ppm for 12 h) & 23.4 & 30.0 \\
\hline
\end{tabular}


Table 3. Phenolic acids and flavonoids identified in 1\% (w/v) propolis solution

\begin{tabular}{|c|c|c|c|c|}
\hline No. & Identified compound & $\begin{array}{c}\text { Retention time } \\
\text { / min }\end{array}$ & $\begin{array}{l}\text { Concentration / } \\
\text { mg mL } \mathbf{~}^{-1} \text { extract }\end{array}$ & $\begin{array}{c}\text { Similarity with } \\
\text { standards }\end{array}$ \\
\hline 1 & p-OH-benzoic acid & 8.49 & 0.63 & 0.995 \\
\hline 2 & Vanillin & 12.98 & 1.43 & 0.991 \\
\hline 3 & Caffeic acid & 19.72 & 52.89 & 0.999 \\
\hline 4 & Ferulic acid & 24.87 & 72.12 & 0.992 \\
\hline 5 & t-Cinnamic acid & 27.50 & 156.48 & 0.999 \\
\hline 6 & Naringenin & 29.26 & 36.05 & 0.992 \\
\hline 7 & Quercetin & 29.99 & 1.87 & 0.990 \\
\hline 8 & Apigenin & 34.57 & 3.33 & 0.999 \\
\hline 9 & Kaempherol & 35.02 & 2.49 & 0.997 \\
\hline 10 & Kaempherol-3-rhamnosid & 35.47 & 2.56 & 0.996 \\
\hline 11 & Pinocembrin & 37.75 & 130.74 & 0.998 \\
\hline 12 & Chrysin & 40.02 & 75.96 & 0.999 \\
\hline 13 & Galangin & 40.91 & 139.11 & 0.997 \\
\hline 14 & Pinostrobin & 44.23 & 225.77 & 0.988 \\
\hline
\end{tabular}

